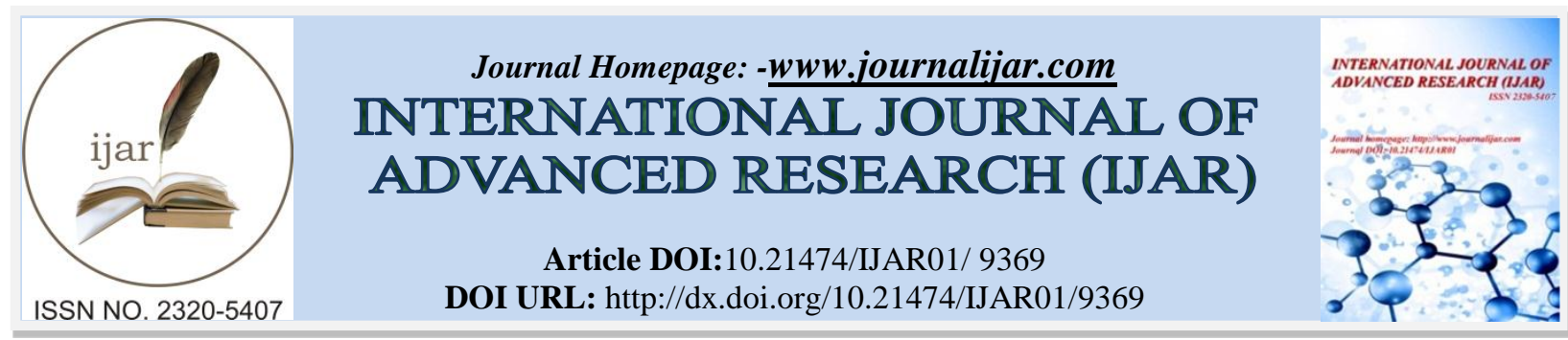

RESEARCH ARTICLE

\title{
OBSTRUCTIVE SLEEP APNOEA IN CHILDREN WITH ADENOID HYPERTROPHY.
}

\section{Merwin Paul. $\mathbf{R}^{1}$, Shobha. $K^{1}$, Srinivasan $K^{1}$ and Vivekanandhan. $B^{2}$.}

1. Department of Otorhinolaryngology, Saveetha Medical College, Chennai.

2. Department of Otorhinolaryngology, Sri Ramachandra Medical College and Research Institute, Chennai.

\section{Manuscript Info}

\section{Manuscript History}

Received: 10 May 2019

Final Accepted: 12 June 2019

Published: July 2019

Key words:-

Adenoid hypertrophy, Obstructive sleep apnea, OSA questionnaire.

\section{Abstract}

The objective of this study was To estimate the prevalence of Obstructive Sleep Apnoea (OSA) in children with adenoid hypertrophy using OSA screening questionnaire. This cross-sectional observational study was done in 50 children who visited the ENT department in a tertiary care teaching hospital in south India. The following data like: demographic details, OSA questionnaire filled by the parent, lateral radiograph of neck to assess adenoid size were collected. Fourteen percentage of children had a score of $>0.33$ in the questionnaire which is suggestive of presence of OSA. Adenotonsillar hypertrophy was found to be a risk factor of OSA in children.

Copy Right, IJAR, 2019,. All rights reserved.

\section{Introduction:-}

Obstructive sleep apnea (OSA) in children is a respiratory disorder characterized by upper airway collapse during sleep. ${ }^{1}$ Adenotonsillar hypertrophy (ATH) is one of the most common cause of OSA in children. The prevalence of OSAS in children peaks at $3-7$ years of age parallel to the age of adenotonsillar enlargement. Untreated OSA is associated with adverse cardiovascular, neurocognitive, and somatic growth consequences. ${ }^{2}$

The upper airway morphology is influenced by adenotonsillar and facial growth patterns which can cause the development of OSA in children of different ages and levels of adiposity. The magnitude of adenotonsillar effects on childhood OSA can be altered by age and obesity. There is not much data on OSA in children secondary to ATH. ${ }^{1}$ Hence this study was conducted with the following objective.

\section{Objective:-}

To estimate the prevalence of Obstructive Sleep Apnoea (OSA) in children with adenoid hypertrophy using OSA screening questionnaire.

\section{Methods:-}

1. Observational cross-sectional study

2. Sample size: 50 children

3. Place: Department of Otorhinolaryngology, Saveetha Medical College

4. Children of age $\leq 18$ years and of either gender with adenoid hypertrophy (> $50 \%$ of airway obstruction) were included in the study

5. The following data like: demographic details, OSA questionnaire ${ }^{3}$ filled by the parent, lateral radiograph of neck to assess adenoid size were collected

Corresponding Author:-Dr. Merwin Paul. R.

Address:-Department of Otorhinolaryngology, Saveetha Medical College, Chennai. 
6. Data is presented as descriptive statistics

\section{Results:-}

Figure 1:

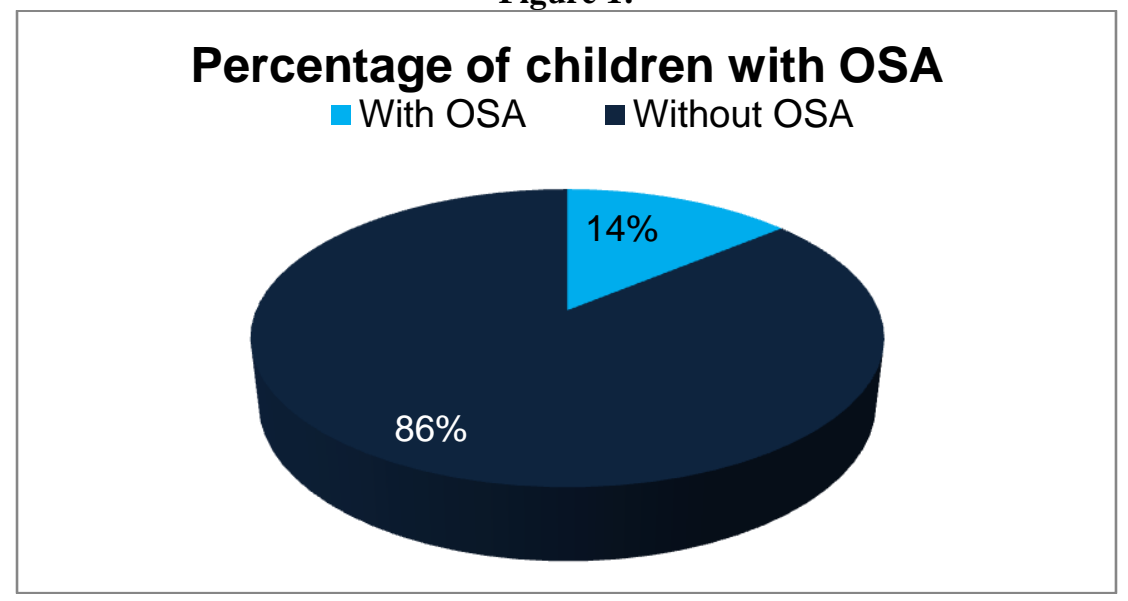

Figure 1 shows the percentage of children who had apnoeic episodes at night. Out of the 50 children 7 had a score of $>0.33$ in the OSA questionnaire, which is suggestive of OSA.

Figure 2:-

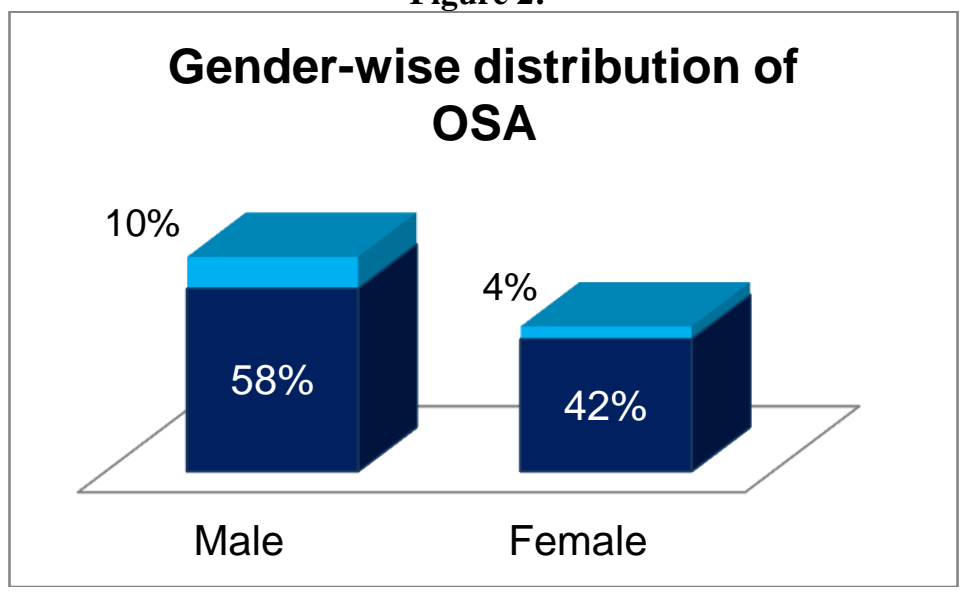

Figure 2 shows the gender wise distribution of OSA among the children. Of the $58 \%$ male children in this study, $10 \%$ had OSA and out of $42 \%$ of female children $4 \%$ had OSA. The p-value was 0.6667 , which was not significant.

Figure 3:

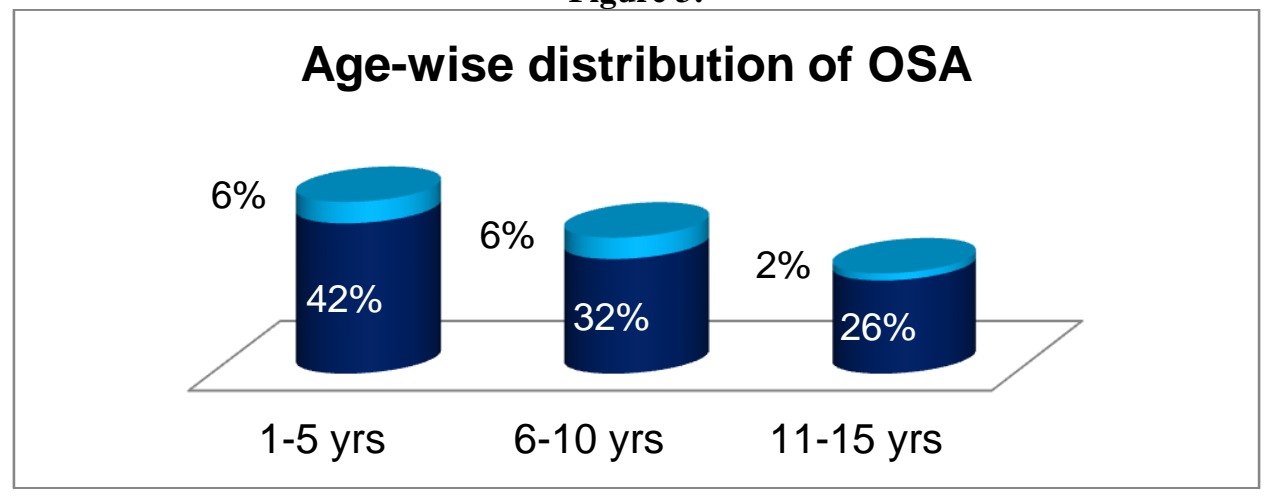


Figure 3 shows the age distribution of OSA. Seventy four percentage of children were in the age group of 1-10 years, $12 \%$ of them had OSA. Only $26 \%$ of the children were between the age of $11-15$ years and $2 \%$ of them had OSA. The p-value was 0.6201 , hence it was not significant.

Figure 4:-

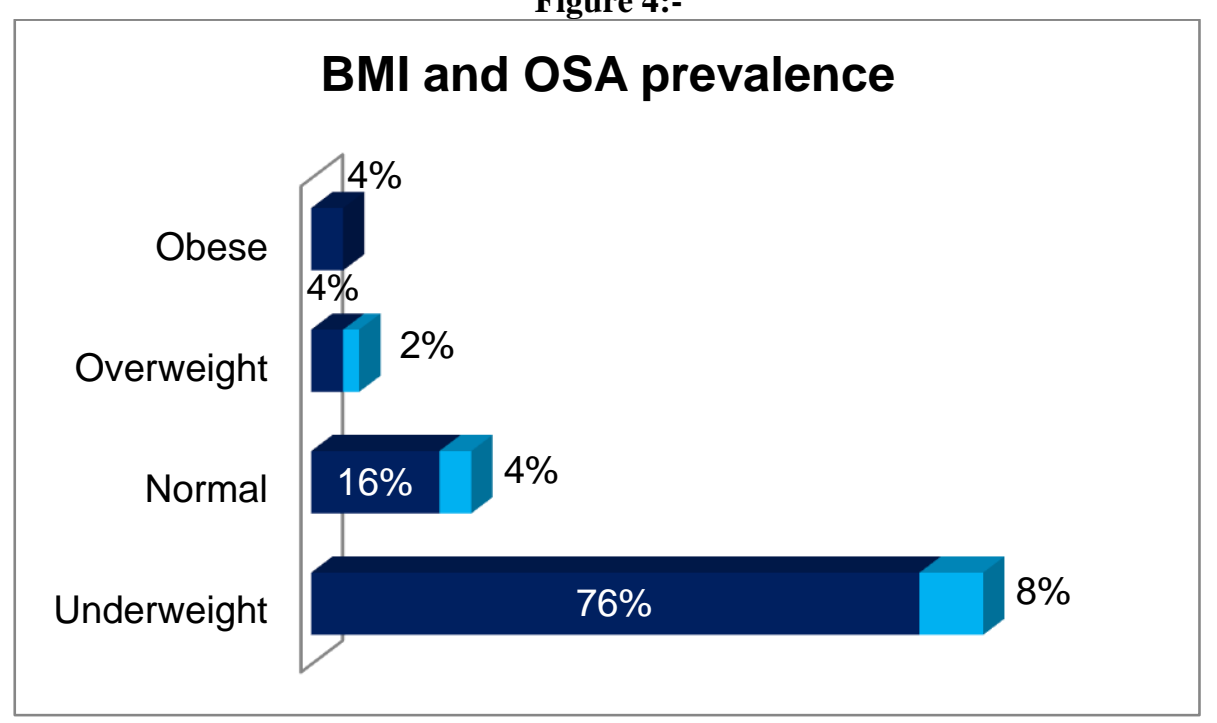

Figure 4 shows the prevalence of OSA based on the BMI. We categorized the children based on their BMI as underweight, normal, overweight and obese. Majority of children ie $76 \%$ were underweight, $8 \%$ of them had OSA. Sixteen percentage of children had normal BMI and $4 \%$ of them had OSA. Four percentage of children fell under the obese category and no one had OSA. The p-value was 0.1478 , which was also not significant.

\section{Discussion:-}

Adenotonsillar hypertrophy is a major determinant for the development of OSA in children. ${ }^{1}$ In this study we estimated the prevalence of Obstructive Sleep Apnoea (OSA) in children with adenoid hypertrophy using a simple bedside OSA screening questionnaire.

In our study forty three children had a score $<0.33$ in the OSA questionnaire. This score suggests that these children are free from apnoeic episodes during night. The rest of the 7 children were found to have a score of $>0.33$ in the OSA questionnaire.

In our study $58 \%$ were males and $42 \%$ were female children, this was similar to the study conducted by Greenfield et $\mathrm{al}^{2}$ In the study conducted by Kang et al ${ }^{1}$ male children were much higher $69.5 \%$, compared to our study. There was no significant difference in the presence of OSA between the male and female children.

We found that $12 \%$ of the children between the age group of 1-10 years had OSA, which was comparable to the study done by Kobayashi et al ${ }^{4}$ where $17 \%$ of children in the same age group has OSA.

In our study we did not find any significant difference in the prevalence of OSA between the obese and non-obese children. A similar result was reported by Kang et $\mathrm{al}^{1}$ in their study as well.

\section{Conclusion:-}

Fourteen percent of all children with adenoid hypertrophy in lateral radiograph of neck had a score of $>0.33$ in the OSA questionnaire. There is no significant difference between gender, age or BMI, and prevalence of OSA in these children. Adenoid hypertrophy has an impact in the development of OSA in children.

\section{References:-}

1. Kang K, Chou C, Weng W, Lee P, Hsu W. Associations between Adenotonsillar Hypertrophy, Age, and Obesity in Children with Obstructive Sleep Apnea. PLoS ONE. 2013;8(10):e78666. 
2. Greenfeld M, Tauman R, DeRowe A, Sivan Y. Obstructive sleep apnea syndrome due to adenotonsillar hypertrophy in infants. International Journal of Pediatric Otorhinolaryngology. 2003;67(10):1055-60.

3. Mindell JA \& Owens JA (2003). A Clinical Guide to Pediatric Sleep: Diagnosis and Management of Sleep Problems. Philadelphia: Lippincott Williams \& Wilkins

4. Kobayashi R, Miyazaki S, Karaki M, Hoshikawa H, Nakata S, Hara H et al. Obstructive sleep apnea in Asian primary school children. Sleep and Breathing. 2013;18(3):483-489. 